\title{
Sperm Transfer in the Sessile Gastropod Serpulorbis (Prosobranchia: Vermetidae)*
}

\author{
A. Scheuwimmer** \\ Institute of Biological Sciences, The University of Tsukuba, Sakura-mura, Ibaraki 300-31, Japan
}

\begin{abstract}
The mechanism of internal fertilization in vermetids has long remained obscure because these sessile gastropods are attached to the substrate throughout their adult life. In addition, in Serpulorbis imbricatus spermatozoa production and egg laying occur in different seasons. In this study the following observations of the unique manner of sperm transfer in two Japanese species of Serpulorbis were made: The males produce spermatophores and expel them from the mantle cavity. A spermatophore consists of two concentric transparent spheres. The inner sphere contains the sperm mass, which is enclosed in a sperm sac. Spermatophores drifting in sea water are caught on mucus strings employed by Serpulorbis for food-particle collection. The mucus strings are hauled in and eaten together with the attached food particles. When, in this way, the spermatophore comes close to the mouth of the gastropod, the spermatophoral spheres are injured by jaws and radula, and the sperm sac is expelled from the inner sphere, guided by an extrusive tube. In the intact spermatophore, this tube lies inverted within the inner sphere. Then the sperm sac enters the mantle cavity in the inhalant respiratory current; the sperm mass is set free, and the spermatozoa can be carried into the slit-shaped female opening by the ciliary current of the pallial gonoduct. The typical spermatozoa stored within the females remain viable until fertilization. The PAS-positive granules of the atypical spermatozoa decrease in volume during sperm transfer and during storage in the female gonoduct. Finally the atypical spermatozoa disintegrate. It is assumed that they serve as 'trophocytes' for typical spermatozoa, as suggested by earlier authors for other prosobranch species.
\end{abstract}

\section{INTRODUCTION}

It is not easy to imagine how the sessile marine prosobranchs of the family Vermetidae can achieve internal fertilization. Hence Mörch (1861) assumed: "Some species ... seem ... to 'decollate' the shell and live afterwards free in the mud; perhaps this may have relation to the sexual functions." More recently, sperm transfer in vermetids was considered to happen in the following way: The spermatozoa are shed into the water by the males and they enter the female mantle cavity, driven by the inhalant respiratory current (Morton, 1951, 1965; Keen and Morton, 1960). Hadfield (1966) briefly described spermatophores of Serpulorbis squamigerus and Petaloconchus montereyensis. However, the sac-like structure he describes in case of $S$. squamigerus looks very much like the sperm sac, i. e. the innermost component of the intact spermatophores of the two species of Serpulorbis described in the present paper. As Hadfield could not observe the transfer of spermatozoa, many problems remained to be

\footnotetext{
- Contribution from the Shimoda Marine Research Center No. 343

- Present address: Zoologisches Institut, Universität Wien, Dr-Karl-Lueger-Ring 1, A-1010 Wien, Austria
}

clarified. This study was undertaken in order to (1) investigate adaptations facilitating internal fertilization in these sessile snails including that in females far away from the nearest male and (2) to shed light on the still obscure fate or function of atypical spermatozoa.

In two Japanese species of Serpulorbis I found very elaborate, planktonic spermatophores and observed their transfer from the male to the female. This paper also reports on the reactions which these spermatophores undergo, and some observations on the structural changes of the atypical spermatozoa during transfer from the male to the female and during the period of storage within the female.

\section{MATERIALS AND METHODS}

This study was performed at the Shimonda Marine Research Center of The University of Tsukuba, in Shimoda, Shizuoka Prefecture, Japan. The organisms used were the vermetids Serpulorbis imbricatus (Dunker) and Serpulorbis sp. which will be described as a new species in another paper. They were collected monthly from the Susaki and Oura beaches near the Research Center. $S$. imbricatus is abundant in the 
intertidal rocky sections of these beaches, but $S$. sp. is not abundant. During low tide the vermetids were carefully removed from the surface of the rock without breaking their shells, or, whenever possible, rock fragments with the shells still attached were broken off. The vermetids were carried to the laboratory and kept in aerated glass aquaria with natural sea water. Observations of the transfer behavior of spermatophores were made on individuals kept in the aquaria for about one month after each collection.

Spermatophores were removed from the aquaria by use of a pipette for further microscopic observation.

\section{RESULTS}

\section{Structure of Spermatophore}

A newly-shed spermatophore of Serpulorbis imbricatus (Fig. 1) consists of the following principal parts: outer sphere, inner sphere, extrusive tube and sperm sac (Fig. 2). The sperm sac contains the cigarshaped sperm mass, which consists of typical and atypical spermatozoa like the sperm mass in the vas deferens. The length of the sperm mass is usually 2.5 to 3 $\mathrm{mm}$ and the average maximal diameter is about 0.3 mm. It is covered by a thin layer of mucus; the wall of the sperm sac is an elastic membrane. The posterior

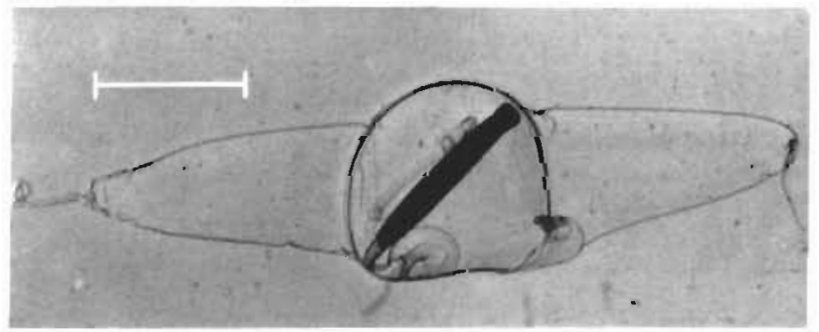

Fig. 1. Serpulorbis imbricatus. Photograph of newly-shed spermatophore. (Scale bar $=2 \mathrm{~mm}$ ) portion of the sac is filled with a jelly-like substance. Anteriorly the wall of the sperm sac is thickened, and contains some small vesicles. In many newly shed spermatophores this part is swollen and of foamy appearance. (For orientation see below.) The inner sphere of 3 to $4 \mathrm{~mm}$ in diameter, in which the sperm sac is contained, consists of two thin membranes, 50 to 100 $\mu \mathrm{m}$ apart. In one area there is a predetermined site of

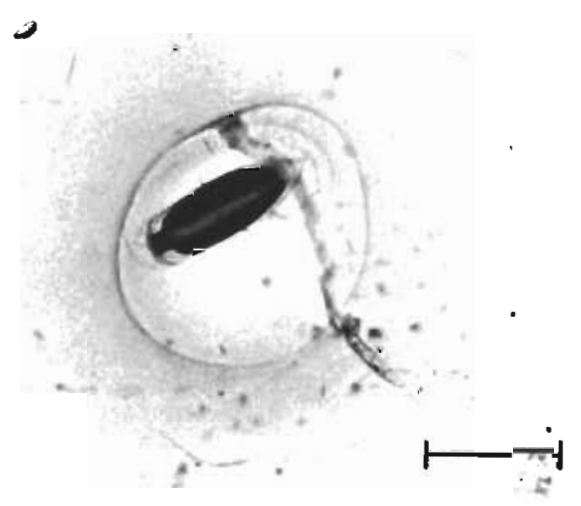

Fig. 3. Serpulorbis sp. Photograph of newly-shed spermatophore. (Scale bar $=1 \mathrm{~mm}$ )

rupture from which the extrusive tube arises. This tube of 6 to $8 \mathrm{~mm}$ length lies coiled up within the inner sphere. The outer membrane of the inner sphere forms a bulge in one place from which a coiled cord arises, connecting this membrane with the outer sphere. The outer sphere is made up of a thin and sticky membrane with a peculiar double cone shape. The whole spermatophore is filled with a clear liquid and completely transparent, with the exception of the sperm mass.

In Serpulorbis sp. the spermatophore consists of the same principal parts as in S. imbricatus, with some differences, e. g., a shorter sperm mass (about $1.0 \mathrm{~mm}$ long), and an egg-shaped outer sphere which is not in contact with the inner sphere (Fig. 3).

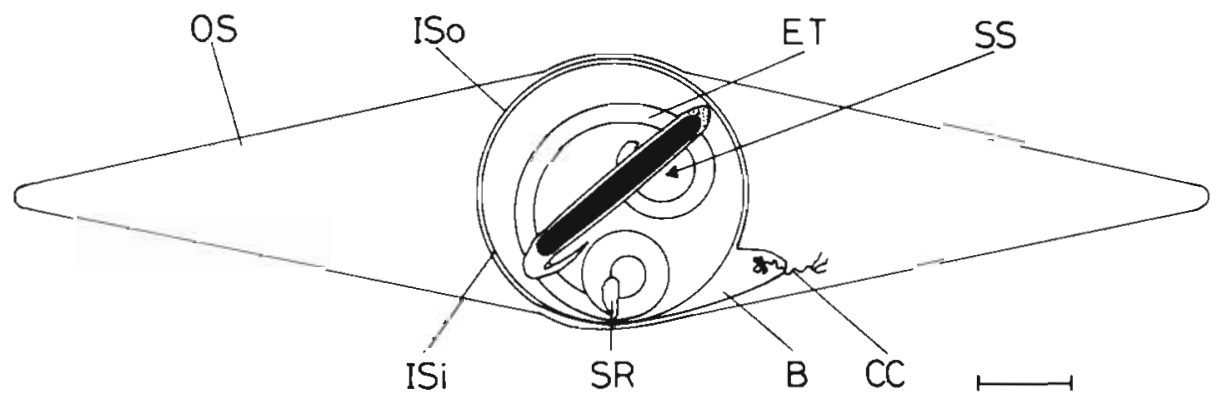

Fig. 2. Serpulorbis imbricatus. Diagrammatic representation of intact spermatophore. The sperm sac (SS) and the extrusive tube (ET), which arises at the preformed site of rupture (SR), are contained within the double-layered inner sphere (ISi and ISo). The outer layer of the inner sphere (ISo) forms a bulge (B) from which the connecting cord (CC) leads to the outer sphere (OS). (Scale bar $=1 \mathrm{~mm}$ ) 


\section{Transfer and Reactions of Spermatophore}

The shedding of spermatophores in Serpulorbis imbricatus was observed for the first time on March 1 , 1979, three days after the vermetids had been carried to the laboratory from Susaki beach. In both species studied, the spermatophore is expelled from the mantle cavity of the male, presumably by a sharp increase in water pressure. This sudden high pressure in the mantle cavity appears to result from a swift retraction of the cephalic and pedal regions into the mantle cavity, as when fecal pellets are expelled. In one male of $S$. imbricatus, a presumably complete series of spermatophore shedding was observed; 8 spermatophores were expelled, and the intervals between successive expulsions of single spermatophores were $8,10,8,10$, 9,9 and $12 \mathrm{~min}$. In a presumably complete series of spermatophore shedding in $S$. sp., 10 spermatophores were expelled, at intervals of $7,6,8,7,5,7,7,8$ and 8 min. In almost all observations in both species the intervals between two successive expulsions within a series were found to be between 5 and $10 \mathrm{~min}$.

In both species shedding of spermatophores can be induced by causing strong turbulence of the water in the aquarium. Shedding of the spermatophores starts about 30 to $60 \mathrm{~min}$ after the water was agitated. When aeration of the aquarium is stopped to eliminate currents, the newly-shed spermatophores sink slowly to the bottom at a maximum horizontal distance of about $20 \mathrm{~cm}$ from the shell aperture of the animal that has expelled them. But when there is even weak water turbulence, they continue drifting for a long time; when a drifting spermatophore comes into contact with the mucus strings which are employed by Serpulorbis for the collection of food particles, it sticks firmly to the mucus (Fig. 4). When the mucus strings with the attached particles and spermatophores are hauled in by the vermetids to be eaten, the outer sphere of the spermatophore is damaged by jaws and radula, but remains connected to the inner sphere by the connecting cord. When the inner sphere is exposed to pressure, it ruptures at the point of origin of the extrusive tube, which then is extruded through this opening in a way similar to the inversion of a glove finger. The contents of the inner sphere, including the sperm sac, pass through the extrusive tube; the diameter of the inner

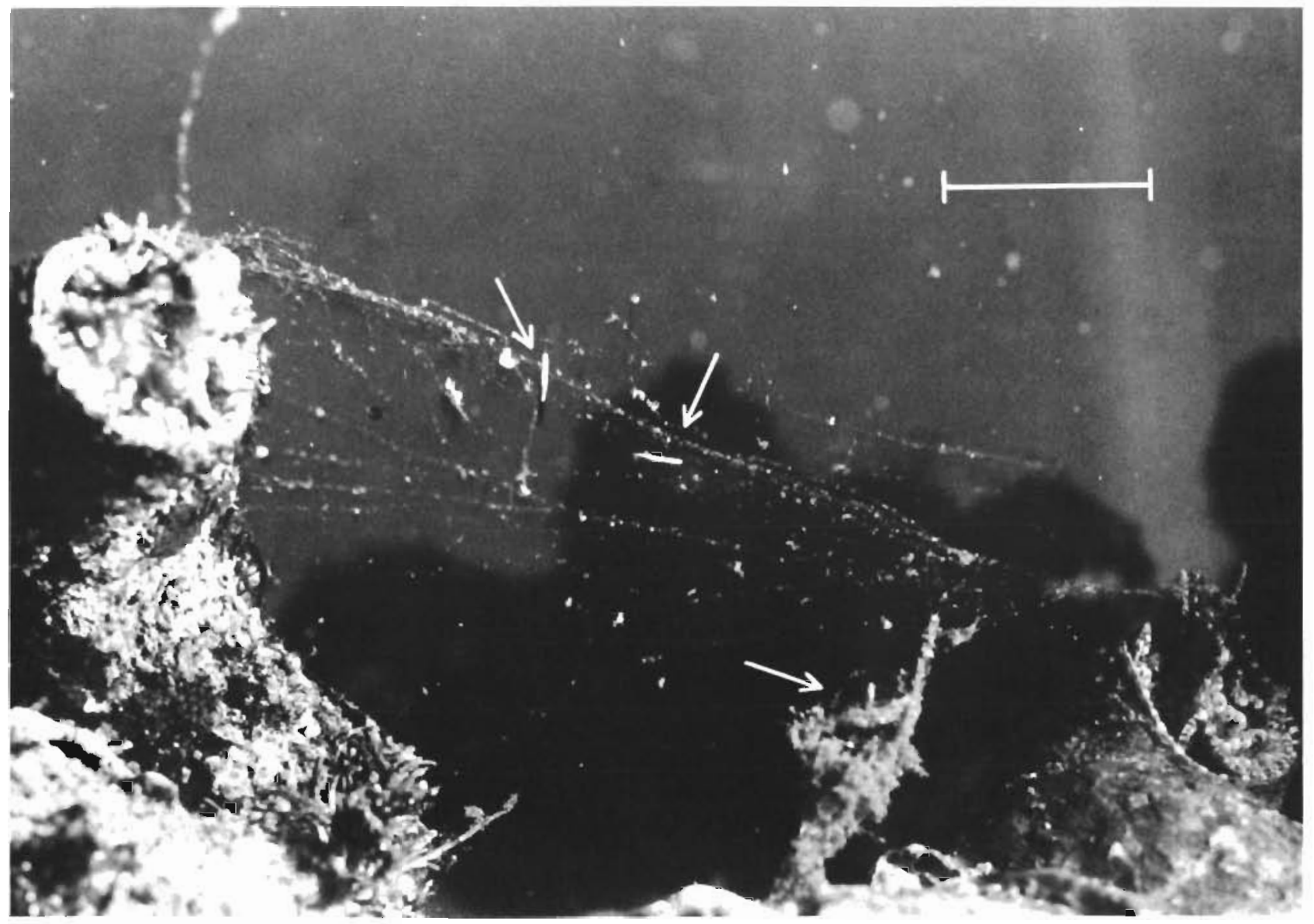

Fig. 4. Serpulorbis imbricatus. Spermatophores (arrows) caught in web of mucus strings between two individuals. (Scale bar $=$ $10 \mathrm{~mm}$ ) 
a
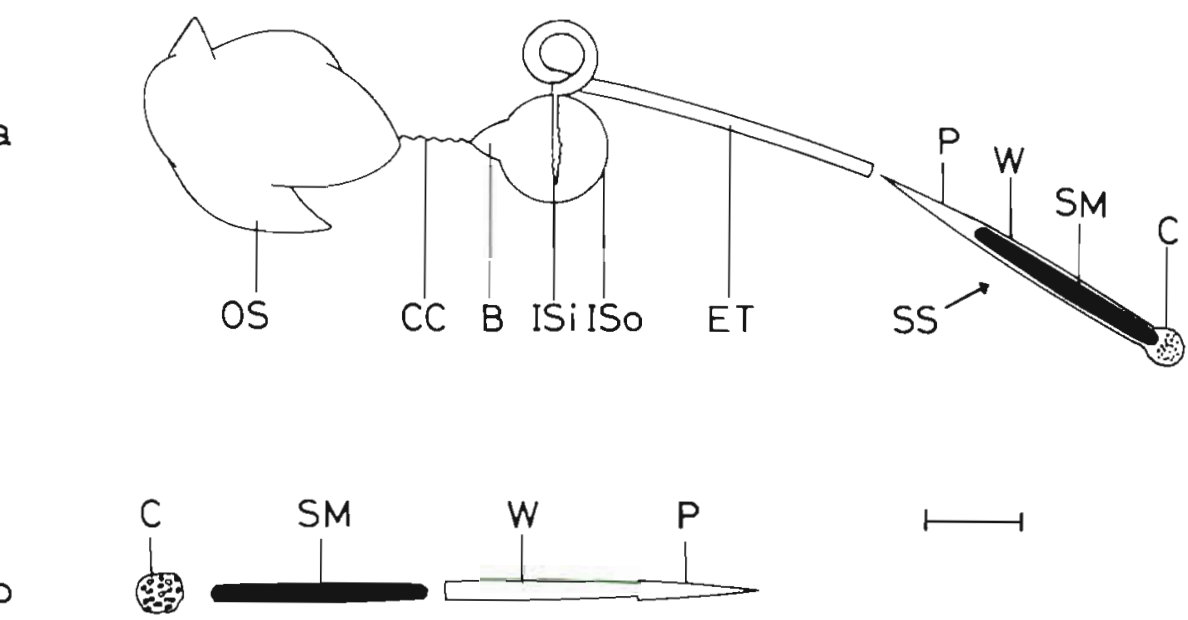

Fig. 5. Serpulorbis imbricatus. Diagrammatic representation of the steps leading to the liberation of the sperm mass. (a) Expulsion of the sperm sac, which consists of sperm mass (SM), cap (C), wall (W) and posterior portion (P); outer sphere damaged, inner sphere shrunken. (b) Sperm mass set free from the sperm sac. (Scale bar $=1 \mathrm{~mm}$ )

sphere rapidly decreases, the lumen within the inner layer of the inner sphere almost disappears and the layer itself takes on a wrinkled or striated appearance (Fig. 5a). The end of the sperm sac which passes first through the extrusive tube is termed anterior. In this way the sperm sac is freed from the mucus strings, and then enters the mantle cavity through the left opening, presumably driven by the respiratory current. It was observed that one female of $S$. imbricatus needed only about 2 min to 'crack' three spermatophores that were caught in her mucus strings, and to drive the sperm sacs into her mantle cavity.

The events that are presumed to take place subsequently in the mantle cavity could not be observed directly. Therefore microscopic observations were made on sperm sacs that were secured from the inhalant respiratory openings of Serpulorbis imbricatus and on others that were obtained by mechanically rupturing spermatophores under the dissecting microscope. All sperm sacs of $S$. imbricatus showed the same sequence of events when observed in a dish with sea water. The anterior end of the sperm sac was observed to swell to a foamy cap, the wall of the sperm sac posterior to the cap gradually retracting, exposing the thinly mucus-covered sperm mass. About 5 to $10 \mathrm{~min}$ after the start of this reaction the now completely retracted wall of the sperm sac with the jelly-like mass in its posterior portion and the swollen cap both separate from the sperm mass (Fig. 5b). Finally, it was observed that the sperm mass thereafter gradually lost its distinct cigar-like shape as the spermatozoa contained within became more and more active in their movements. While enclosed in the sperm sac no movements of the typical and atypical spermatozoa could be observed.

\section{Morphological Changes of Atypical Spermatozoa}

Sperm samples of both species were taken from the vas deferens, from newly-shed spermatophores and from spermatophores that had been caught on algal matter and were known to have been attached without damage for up to several days before observation of the sperm mass. Sperm samples were also taken from the pallial gonoducts of females. It was found that the typical spermatozoa were of the same appearance in
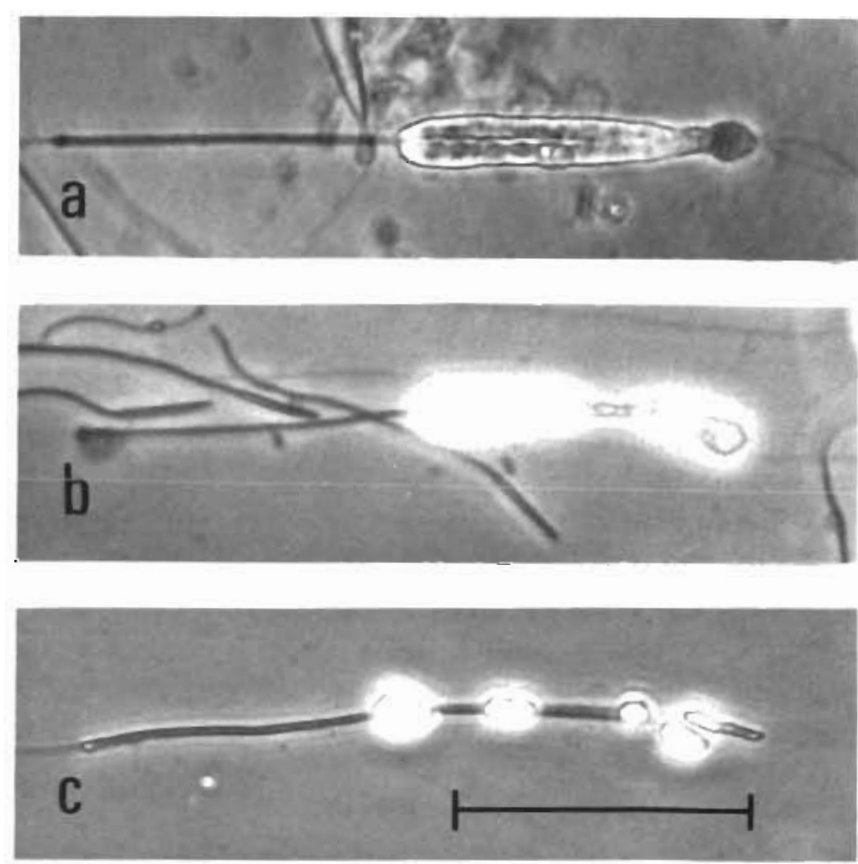

Fig. 6. Serpulorbis imbricatus. Atypical spermatozoa; (a) from vas deferens; (b) from spermatophore; (c) from female pallial gonoduct. (Scale bar $=30 \mu \mathrm{r}$ ) 
all samples examined, but morphological differences of the atypical spermatozoa were observed, depending on the origin of the sample. The big granules of the atypical spermatozoa, which are strongly PAS-positive in Serpulorbis imbricatus (Tochimoto, 1967), and also in $S$. sp. (unpublished), were in full size only in the vas deferens and in newly shed spermatophores (Fig. 6a); in spermatophores that had drifted in the aquarium for some days before observation, the granules showed decrease in size, but the structure of the atypical spermatozoa was still intact (Fig.6b). Atypical spermatozoa from the female pallial gonoduct had very reduced granules and most of the atypical spermatozoa were in fact disintegrated (Fig. 6c).

\section{DISCUSSION}

All monotocardians are said to exhibit internal fertilization and many of them are known to practice copulation. As the vermetids are sessile throughout their adult life and lack a penis, copulation can be ruled out as a mode of sperm transfer. Morton (1951, 1965) thought that the spermatozoa are released into the water by the male and then carried into the mantle cavity of the female in her respiratory current. This possibility might be considered in gregarious populations only. Hadfield (1966) briefly described a spermatophore of Serpulorbis squamigerus, but his illustration closely resembles the expelled sperm sac of $S$. imbricatus studied here; it is assumed that he could not obtain an intact spermatophore. His representation of the spermatophore of Petaloconchus montereyensis looks more like an intact spermatophore.

The author made a preliminary investigation in June 1978. Females of Serpulorbis imbricatus that were at least $30 \mathrm{~cm}$ apart from the nearest vermetid were selectively collected, and their pallial gonoducts were examined. It was found that 8 out of 10 had sperm masses in their seminal receptacles. From similar findings, Hadfield (1966) considered among other possibilities that of sex reversal followed by self-fertilization with stored autospermatozoa. Indeed, successful fertilization of such isolated vermetid females is barely imaginable if the spermatophores were mere containers of sperm mass as in other gastropods. When such a simple 'sperm container' is caught on the mucus strings employed for feeding, it will most probably be eaten by the vermetid like the other particles attached.

In Serpulorbis, there are two main adaptations that assure successful sperm transfer. First, the spermatophores are able to stay afloat for a long time. This is achieved by a specific gravity close to that of sea water, and by the large outer sphere. Thus even females that are far away from the nearest male can be fertilized, facilitating the spreading of the population. The second adaptation is the expulsion mechanism, presumably powered by the contraction of the inner sphere. In this way the sperm sac comes free from the sticky mucus strings to escape the fate of being eaten and can enter the mantle cavity. The extrusive tube, through which the sperm sac is expelled, protects the sperm sac against sticking to the mucus strings after leaving the inner sphere. As the tube is very elastic, it is thought to bend in the direction of the inhalant respiratory current as early as during the phase of inversion and extrusion, and thus will guide the sperm sac to the inhalant opening of the mantle cavity.

After liberation from the sperm sac the spermatozoa are thought to enter the long, slit-shaped female opening. The cells of the distal portion of the pallial gonoduct bear strongly beating cilia. These cause a current that can carry the spermatozoa from the mantle cavity into the gonoduct and finally into the seminal receptacle, which is a pouch of the proximal portion of the female pallial gonoduct. It was observed that the fluid within the inner sphere of the spermatophore has optical characteristics different from those of sea water, and therefore it is assumed that the reaction of the sperm sac (swelling of the anterior cap and retraction of the wall of the sperm sac) is triggered by the osmotic differences between the liquid within the inner sphere and the sea water into which the sperm sac is expelled. In many spermatophores, however, a minor foamy cap on the anterior end of the sperm sac was already present when examined immediately after shedding. But in these cases (e.g. Fig. 1) the reaction did not proceed further unless the sperm sac was expelled into the sea water. The observation that shedding of spermatophores could be induced by causing strong turbulence of the water coincides well with the fact that the production of mucus strings can often be induced by the same action. However, while a male Serpulorbis is engaged in shedding of spermatophores he never seems to produce or employ mucus strings.

This type of sperm transfer seems to be nonspecific in some aspects; e.g. it was observed that an individual of Serpulorbis imbricatus caught spermatophores of $S$. sp. in its mucus strings and that the sperm sacs finally entered the mantle cavity. It is even possible that individuals that were seen accepting spermatophores into their mantle cavities were in fact males, because frequently the sex of a specimen cannot be stated safely without removing the animal from the shell. However, out of several S. imbricatus that were observed to accept sperm sacs, three individuals were removed from their shells and were all found to be female.

As first reported by Nishiwaki (1969) and confirmed by the author's own observations, the testes of Ser- 
pulorbis imbricatus develop from September to February and degenerate from May to August, while the ovaries develop from April to August and degenerate from November to February. Egg laying is most active in June and July, when no spermatozoa are produced by the males. This time difference between male and female reproductive season is considered to make storage of spermatozoa within the females necessary. The observations concerning the decrease in volume of the granules of the atypical spermatozoa seem to indicate that these atypical spermatozoa function as a kind of trophocyte for the typical spermatozoa, important during the long periods that the spermatophores might float free as well as during storage within the females. Earlier reports on other prosobranch species also indicate a nutritive function for atypical spermatozoa, e.g. Reinke (1914) for Strombus bituberculatus; Hanson et al. (1952) for Viviparus viviparus; Battaglia (1953) for Columbella rustica; Bulnheim (1962) for Opalia crenimarginata, Scala clathrus and Janthina pallida; and Bulnheim (1968) for Epitonium tinctum. Hadfield (1966) reported that all atypical spermatozoa of $S$. squamigerus disintegrate within the male pallial gonoduct; he assumed the granules of the disintegrated atypical spermatozoa are incorporated in a layer of the spermatophoral wall, and he discussed their possible function as a nutrient for the typical spermatozoa. He found that the sperm masses contained in spermatophores of S. squamigerus consisted only of typical spermatozoa. In the two Japanese species of Serpulorbis studied in the present paper, all spermatophores investigated contained both typical and atypical spermatozoa.

Acknowledgements. I wish to express my sincere gratitude to Professor Y. Watanabe (Institute of Biological Sciences) and Professor S. Nishiwaki (College of Medical Technology and Nursing) of The University of Tsukuba for their constant guidance throughout my studies in Japan. Special thanks are due to the staff of the Shimoda Marine Research Center of The University of Tsukuba, particularly its director, Professor $\mathrm{H}$. Watanabe, for the hospitality during $m y$ research there.
Heartfelt thanks go to Dr. T. Makioka for his assistance in numerous instances. Finally, I wish to express my gratitude for a research scholarship from the Japanese Ministry of Education (Monbusho).

\section{LITERATURE CITED}

Battaglia, B. (1953). Il significato della presenza di polisaccharidi negli spermatozoi atipici dei Gasteropodi Prosobranchi. Ricerca scient., 23 (Suppl.), 125-129.

Bulnheim, H.-P. (1962). Untersuchungen zum Spermatozoendimorphismus von Opalia crenimarginata (Gastropoda, Prosobranchia). Z. Zellforsch. 56, 300-343.

Bulnheim, H.-P. (1968). Atypische Spermatozoenbildung bei Epitonium tinctum. Helgoländer wiss. Meeresunters. 18, 232-253.

Hadfield, M. G. (1966). The reproductive biology of the California vermetid gastropods Serpulorbis squamigerus (Carpenter, 1857) and Petaloconchus montereyensis Dall, 1919. Ph. D. thesis, Stanford University.

Hanson, J., Randall, J. T., Bayley, S. T. (1952). The microstructwre of the spermatozoa of the snail Viviparus. Exp. Cell. Res. 3, 65-78.

Keen, A. M. and Morton, J. E. (1960). Some new African species of Dendropoma (Vermetidae: Mesogastropoda). Proc. malac. Soc. Lond., 34, 36-51.

Mörch, O. A. L. (1861). Review of the Vermetidae. (Part I). Proc. zool. Soc. Lond., 30, 145-181.

Morton, J. E. (1951). The structure and adaptations of the New Zealand Vermetidae. I. The genus Serpulorbis. Trans. $R$. Soc. N. Z., 79, 1-19.

Morton, J. E. (1965). Form and function in the evolution of the Vermetidae. Bull. Br. Mus. nat. Hist. (Zoology), 11, 585-630.

Nishiwaki, S. (1969). Seasonal size variations of the pallial slit in the female Serpulorbis imbricatus (Prosobranchia, Vermetidae). Sci. Rep. Tokyo Kyoiku Daig. (Sect. B), 14, $69-78$

Reinke, E. E. (1914). The development of the apyrene spermatozoa of Strombus bituberculatus. Publs. Carnegie Inst., 183, 195-239.

Tochimoto, T. (1967). Comparative histochemical study on the dimorphic spermatozoa of the Prosobranchia with special reference to polysaccharides. Sci. Rep. Tokyo Kyoiku Daig. (Sect. B), 13, 75-109. 